\title{
Influência do $\mathrm{CO}_{2}$ via água de irrigação e da cobertura plástica no solo na Abobrinha ${ }^{1}$
}

\author{
Influence of $\mathrm{CO}_{2}$ applied with the irrigation water and plastic mulch on Summer \\ Squash
}

\author{
Wellington Farias Araújo ${ }^{2 *}$ e Tarlei Ariel Botrel ${ }^{3}$
}

\begin{abstract}
Resumo - O experimento foi realizado em Piracicaba, SP, com o objetivo de avaliar os efeitos de doses de $\mathrm{CO}_{2}$ aplicadas via água de irrigação associadas ou não a cobertura plástica do solo na produção da abobrinha cultivada em campo aberto. O delineamento foi em blocos completos ao acaso, em esquema de parcelas subdivididas, com o fator $\mathrm{CO}_{2}$ na parcela e o fator cobertura nas subparcelas. Os tratamentos foram constituídos das seguintes doses de $\mathrm{CO}_{2}$ aplicados via água de irrigação: $0 ; 59 ; 148$ e $274 \mathrm{~kg} \mathrm{ha}^{-1}$ de $\mathrm{CO}_{2}$. O sistema de irrigação foi por gotejamento com reposição diária de água, baseada no tanque classe A. As variáveis analisadas foram: área foliar por planta $\left(\mathrm{cm}^{2}\right)$, número de frutos por planta e produtividade $\left(\mathrm{kg} \mathrm{ha}^{-1}\right)$. A interação entre os fatores doses de $\mathrm{CO}_{2}$ e a cobertura do solo apresentaram efeito significativo sobre as variáveis analisadas. A maior produtividade de abobrinha foi de $15.433 \mathrm{~kg} \mathrm{ha}^{-1}$ obtida com o uso de $58,6 \mathrm{~kg} \mathrm{ha}^{-1}$ de $\mathrm{CO}_{2}$ associado à cobertura plástica.
\end{abstract}

Palavras-chave - Cucúrbita pepo L.. Dióxido de carbono. Irrigação por gotejamento. Mulch.

\begin{abstract}
The experiment was carried out in Piracicaba, SP, in order to evaluate the effects of different carbon dioxide levels applied with irrigation water, associated or not to the mulch plastic, on yield of summer squash. The experimental design was in random blocks in split plot design, with the factor levels of $\mathrm{CO}_{2}$ in the plot and the mulch plastic in split-plot. The treatments constituted on the following levels: $0 ; 59 ; 148$ and $247 \mathrm{~kg} \mathrm{ha}^{-1}$ of $\mathrm{CO}_{2}$. The irrigation was scheduled daily based on a tank class A, using a drip irrigation system. The leaf area, the number of fruit and the yield were evaluated. The levels of $\mathrm{CO}_{2}$ and mulch plastic influenced the leaf area; consequently, it provided increment in the number of fruit and yield of summer squash. The best yield of $15,433 \mathrm{~kg} \mathrm{ha}^{-1}$ was obtained by $58.6 \mathrm{~kg} \mathrm{ha}^{-1} \mathrm{of} \mathrm{CO}_{2}$ with the plastic mulch.
\end{abstract}

Key words - Cucurbita pepo L.. Carbon dioxide. Drip irrigation. Mulch.

\footnotetext{
* Autor para correspondência

${ }^{1}$ Recebido para publicação em 07/07/2009; aprovado em 19/04/2010

Projeto financiado pela FAPESP e desenvolvido pela ESALQ

${ }^{2}$ Departamento de Solos e Engenharia Agrícola/UFRR, Boa Vista-RR, Brasil, 69.309-200, wellingtonufrr@gmail.com

${ }^{3}$ Departamento de Engenharia Rural, ESALQ/USP, Piracicaba- SP, Brasil, 13.418-900, tabotrel@esalq.usp.br
} 


\section{Introdução}

A aplicação de $\mathrm{CO}_{2}$ via água ou via ar, tem sido testada com relativo sucesso em hortaliças, em frutíferas e em plantas ornamentais. Embora não seja uma técnica nova, já que os primeiros trabalhos de utilização do $\mathrm{CO}_{2}$ na agricultura datam do começo do século $\mathrm{XX}$, sua adoção, para uso geral, ainda não tem sido recomendada (MOORE, 1990).

A aplicação de $\mathrm{CO}_{2}$ tem promovido aumento da produtividade em pimentão (GURI et al., 1999) e pepino (IBRAHIM,1992); em outras pesquisas o uso do gás não teve efeito significativo sobre as culturas de tomate e pepino (HARTZ; HOLT, 1991), pimentão (STORLIE; HECKMAN, 1996). No Brasil, em experimento de campo, Pinto et al.(2001) obtiveram aumento de até $70 \%$ na produção comercial em melão. Em ambiente protegido, Cararo (2000) verificou um incremento de $8,7 \%$ na produção de tomate. Branco et al. (2007) também trabalhando com tomate obteve aumento na produção de frutos comerciais. Furlan et al.(2002) observaram o aumento no rendimento de pimentão de $51,3 \%$ com aplicação de $\mathrm{CO}_{2}$ via água de irrigação. Rezende et al. (2003) observaram que o $\mathrm{CO}_{2}$ promoveu o aumento da massa fresca e não do número de frutos de pimentão. Para alface em ambiente protegido, Furlan et. al. (2001); Gomes et al. (2005) e Tamagi et al. (2007) observaram aumento de matéria fresca, matéria seca e produtividade com o uso do $\mathrm{CO}_{2}$ via água de irrigação.

Storlie e Heckman (1996) citaram os possíveis mecanismos que levam a cultura ao incremento de produção, quando se trabalha com água carbonatada. Eles são: i) incremento na absorção de alguns elementos na planta; ii) enriquecimento do sistema solo-ar com $\mathrm{CO}_{2}$ que inibe a atividade de etileno melhorando a atividade do sistema radicular; iii) absorção direta do $\mathrm{CO}_{2}$, o que estimula a fotossíntese. Os autores assinalam que o uso da água carbonatada não tem sido ainda recomendado comercialmente devido às poucas pesquisas realizadas em campo e ao desconhecimento de certos mecanismos de ação, que provem resultados diversos, dependendo das condições ambientais.

A cobertura do solo com filme plástico (mulch) em espécies olerícolas torna-se prática importante porque, aumenta a tolerância ao uso de água salina na irrigação (NASCIMENTO et al., 2000), evita o desenvolvimento de ervas daninhas e promove repelência a insetos (SAMPAIO; ARAÚJO, 2001) e proporciona maior desenvolvimento vegetativo e produtividade (SILVA, 2002). Isso ocorre provavelmente pelo maior aquecimento da camada superficial do solo proporcionado pela cobertura plástica em relação ao solo nu, propiciando uma maior absorção de água e nutrientes e, conseqüentemente, um maior crescimento vegetal. Também a cobertura do solo retém a umidade por mais tempo e diminui a evapotranspiração (SAMPAIO; ARAÚJO, 2001).

Dentre as olerícolas, a cultura de abobrinha de moita apresenta-se como uma opção de plantio para os produtores, por possuir boa aceitação no mercado e poder ser cultivada o ano todo. A abobrinha é designação dada ao fruto de cultivares de abóbora, pertencente à espécie Cucurbita pepo L., com hábito de crescimento moita (FILGUEIRA, 2008).

O objetivo do trabalho foi avaliar o feito de diferentes doses de $\mathrm{CO}_{2}$ aplicados via água de irrigação associadas ou não ao uso da cobertura plástica do solo sobre a cultura da abobrinha.

\section{Material e métodos}

O experimento foi conduzido na fazenda Areão, pertencente à Escola Superior de Agricultura "Luiz de Queiroz" (ESALQ) da Universidade de São Paulo (USP) em Piracicaba, São Paulo, cujas coordenadas geográficas de referência são: latitude $22^{\circ} 42^{\prime} \mathrm{S}$, longitude $47^{\circ} 38^{\prime} \mathrm{W}$ e a altitude de $580 \mathrm{~m}$.

O clima da região, segundo a classificação do Köppen, é do tipo Cwa, mesotérmico, subtropical úmido, com estiagem no inverno. O solo da área experimental é classificado como Nitossolo vermelho com declividade média de $2 \%$, apresentando na camada de 0 a $20 \mathrm{~cm}$ de profundidade as seguintes características químicas e físicas: $\mathrm{pH}=4,5 ; \mathrm{Ca}=34 \mathrm{mmol}_{\mathrm{c}} \mathrm{dm}^{-3} ; \mathrm{Mg}=16 \mathrm{mmol} \mathrm{dm}_{\mathrm{c}}^{-3} ; \mathrm{Al}$ $=3,0 \mathrm{mmol}_{\mathrm{c}} \mathrm{dm}^{-3} ; \mathrm{P}=11,0 \mathrm{mg} \cdot \mathrm{dm}^{-3} ; \mathrm{K}=4,8 \mathrm{mmol}_{\mathrm{c}} \mathrm{dm}^{-3}$; M.O. $=31,0 \mathrm{~g} \mathrm{dm}^{-3}$; areia $=250 \mathrm{~g} \mathrm{~kg}^{-1}$; silte $=180 \mathrm{~g} \mathrm{~kg}^{-1}$; argila $=570 \mathrm{~g} \mathrm{~kg}^{-1}$ e densidade aparente de $1,39 \mathrm{~kg} \mathrm{dm}^{-3}$. Baseado nessa análise e seguindo-se recomendação de adubação sugerida por Raij et al. (1996), o calcário dolomítico, com a seguinte composição: $39 \%$ de $\mathrm{CaO}$ e $13 \%$ de $\mathrm{MgO}$ e PRNT 91\%, foi aplicado na quantidade de 3,0 $\mathrm{t} \mathrm{ha}^{-1}$ cinco meses antes do plantio. Uma semana antes do transplante foram aplicados $40 \mathrm{~kg} \mathrm{ha}^{-1}$ de $\mathrm{N} ; 400 \mathrm{~kg} \mathrm{ha}^{-1}$ de $\mathrm{P}_{2} \mathrm{O}_{5}$; $100 \mathrm{~kg} \mathrm{ha}^{-1}$ de $\mathrm{K}_{2} \mathrm{O}$ e $2 \mathrm{~kg}$ de esterco bovino na cova de plantio. Durante o cultivo, um tanque de derivação de fluxo foi empregado para a injeção do fertilizante na água de irrigação, onde a uréia e o nitrato de potássio foram utilizados como adubos aplicados a cada dois dias a partir do $14^{\circ}$ dia após o transplante (DAT) com término aos 52 DAT. O parcelamento total desses fertilizantes foi de 20; 35; 30 e 15\%, baseado no programa de fertirrigação na abobrinha proposto por Hartz e Hochmuth (1996). O adubo correspondente a cada percentual desse foi distribuído em cinco aplicações. Posteriormente, nitrato de cálcio na quantidade de $10 \mathrm{~kg} \mathrm{ha}^{-1}$ foi utilizado como 
preventivo ao surgimento de problemas de "fundo preto" nos frutos, tendo sido parcelado em cinco aplicações a partir dos 44 DAT.

O delineamento experimental foi o de blocos ao acaso num esquema de parcela subdivididas com três repetições. As parcelas constaram das doses de $\mathrm{CO}_{2}(0 ; 59$; 148 e $274 \mathrm{~kg} \mathrm{ha}^{-1}$ de $\left.\mathrm{CO}_{2}\right)$ e as subparcelas das coberturas de solo (com ou sem o uso da cobertura plástica preta de polietileno de 150 micras sobre o solo (mulch).

Cada subparcela teve $5,0 \mathrm{~m}$ de comprimento e 5,0 $\mathrm{m}$ de largura, com cinco fileiras de plantas espaçadas $1,0 \mathrm{~m}$ entre si. Os canteiros contavam com 25 plantas, sendo 9 plantas por subparcela.

A abrobinha (Cucurbita pepo L.) cv. caserta foi semeada em bandejas de polietileno expandido de 144 células. Posteriormente, as mudas foram pré-imunizadas com uma estirpe fraca do vírus PRSV-W (Papaya ringspot vírus type $\mathrm{W}$ ) e, após 10 dias, transplantadas para o local definitivo no espaçamento de 1,0 m entre linhas e 1,0 m entre plantas, quatro dias após a imunização.

A irrigação foi feita com o emprego de fita gotejante queengill instalada na superfície do solo, possuindo as seguintes características: $16,5 \mathrm{~mm}$ de diâmetro interno, espessura da parede de $0,25 \mathrm{~mm}$, pressão de serviço de $60 \mathrm{kPa}$ e vazão nominal de 4,0 $\mathrm{L} \mathrm{h}^{-1} \mathrm{~m}^{-1}$. O manejo da irrigação baseou-se na evaporação do tanque classe $\mathrm{A}$, método utilizado por outros pesquisadores no manejo da irrigação (AZEVEDO et al, 2005; CHAVES et al., 2006; REGO et al, 2009). Considerouse o coeficiente de tanque (Kp) de 0,72 (SENTELHAS et al., 1999) enquanto os coeficientes de cultura (Kc), adaptado de Doorenbos e Pruitt (1997), variam de 0,7 a 0,9, dependendo do estádio da cultura.

$\mathrm{O}$ sistema de aplicação de $\mathrm{CO}_{2}$ foi composto por três cilindros, sendo um para cada tratamento. Havia uma válvula junto ao cilindro, um fluxômentro para quantificar a dose de $\mathrm{CO}_{2}$ a ser injetada e um injetor do tipo venturi ligado à tubulação de água que introduzia o gás à água de irrigação.

A aplicação de água carbonatada teve início aos 6 DAT e findou aos 66 DAT. Para a quantificação do total de dióxido de carbono aplicado, cada tratamento dispunha de seu próprio cilindro, que foi pesado antes e após o experimento. A diferença de peso resultou no total de gás aplicado, posteriormente transformado para $\mathrm{kg} \mathrm{ha}^{-1}$. O tempo de aplicação do gás variou em função da lâmina de irrigação, tendo início quando ocorria pressurização do sistema de irrigação e término com o fim da aplicação da lâmina de água.

Diariamente antes das irrigações, a solução do solo era coletada, conforme descrito por Silva et al. (1999), para posterior leitura do $\mathrm{pH}$ e da condutividade elétrica (CE) da solução do solo.
Durante o trabalho de campo, três plantas de cada tratamento foram escolhidas ao acaso para determinação da área foliar no final do experimento aos 68 DAT. A área foliar foi estimada usando o método não destrutivo proposto por Araújo et al. (2000), pela seguinte equação:

$\mathrm{AF}=0,6181^{*}(\mathrm{LF})^{2}$

Onde,

$\mathrm{AF}$ - área foliar $\left(\mathrm{cm}^{2}\right)$;

LF - largura da folha, cm.

Um geotermômetro foi instalado a $10 \mathrm{~cm}$ de profundidade em cada sub parcela, sendo as leituras realizadas diariamente, antes do início de cada irrigação.

Durante a fase de produção, os frutos foram retirados diariamente no ponto comercial, quantificados e pesados individualmente em cada colheita. A produtividade foi estimada em $\mathrm{kg} \mathrm{ha}^{-1}$ para cada tratamento. A colheita se prolongou por 30 dias após o seu início.

$\mathrm{Na}$ análise dos resultados, foi feita uma análise de variância e, posterior obtenção das equações de regressão para as variáveis quantitativas (doses de $\mathrm{CO}_{2}$ ) e, empregou-se o teste de Tukey a 5\% de probabilidade, para as variáveis qualitativas (com ou sem cobertura plástica). Os dados que não apresentaram uma distribuição normal foram transformadas para $\log \mathrm{x}$.

\section{Resultados e discussão}

A lâmina de água aplicada à cultura foi de 110,0 $\mathrm{mm}$ e o total de chuvas foi de $65,6 \mathrm{~mm}$, resultado num total de 175,6 mm. Durante o período experimental, o total evaporado pelo tanque Classe A foi de 197,6 mm. Com as leituras dos geotermômetros, observou-se que nas parcelas com cobertura plástica, as temperaturas foram superiores, em média, 4,8 ${ }^{\circ} \mathrm{C}$ em relação àquelas sem coberturas plásticas. Resultados similares foram obtidos por AbdulBaki et al. (1992), que observaram um aumento de cerca de $5{ }^{\circ} \mathrm{C}$ com o uso da cobertura plástica.

As análises da solução do solo revelaram em termos médios, ao longo do experimento, os seguintes valores de $\mathrm{pH}: 7,5 ; 7,3 ; 6,8 ; 6,0$ e 5,7 para os tratamentos $0 ; 59 ; 148$ e $274 \mathrm{~kg} \mathrm{ha}^{-1}$ de $\mathrm{CO}_{2}$, respectivamente. Resultados semelhantes foram evidenciados por outros autores, que constataram a redução do $\mathrm{pH}$ da solução do solo com a adição do $\mathrm{CO}_{2}$ (CARARO, 2000; GURI et al., 1999). Segundo Storlie e Heckman (1996), o benefício potencial da água carbonatada é a redução temporária do $\mathrm{pH}$, incrementando a absorção de alguns elementos químicos pela planta. 
A Condutividade elétrica da solução do solo apresentou uma tendência de aumento com a aplicação de água carbonatada, passando de $1,74 \mathrm{dS} \mathrm{m}^{-1}$ no tratamento testemunha a $2,37 \mathrm{dS} \mathrm{m}^{-1}$ no tratamento com o uso de $274 \mathrm{~kg} \mathrm{ha}^{-1}$ de $\mathrm{CO}_{2}$, sugerindo uma maior disponibilidade de nutrientes à cultura. Tendência semelhante foi observada por Cararo (2000), cujos valores de CE para água carbonatada foram sempre superiores à $\mathrm{CE}$ da água controle; enquanto Gomes et al. (2005) não observaram alterações nos valores da $\mathrm{CE}$.

A área foliar foi influenciada significativamente em nível de $5 \%$ de probabilidade pelo teste $\mathrm{F}$ pelos fatores dose e cobertura. A Tabela 1 mostra as equações de regressões ajustadas para a área foliar $\left(\mathrm{cm}^{2}\right)$ da abobrinha aos 68 DAT. Foi possível ajustar um modelo quadrático que explica $57,0 \%$ das variações dentro do solo coberto, obtendo-se para uma dose de $86,3 \mathrm{~kg} \mathrm{ha}^{-1}$ de $\mathrm{CO}_{2}$ uma área foliar por planta de $11.413,25 \mathrm{~cm}^{2}$, enquanto para o solo nu ajustou-se uma dose ótima de $129,8 \mathrm{~kg} \mathrm{ha}^{-1}$ de $\mathrm{CO}_{2}$, resultando numa área foliar por planta de $9.363,25 \mathrm{~cm}^{2}$. Resultados semelhantes foram obtidos por Guri et al. (1999) quando aplicaram $\mathrm{CO}_{2}$ em solução nutritiva e obtiveram incremento na área foliar na cultura do pimentão e acréscimo de $10 \%$ na produtividade. Mudrik et al. (1997) observaram aumento de $30 \%$ na área foliar e $54 \%$ na biomassa de ervilha e atribuíram os resultados à maior disponibilidade de nutrientes mineral à cultura.

O número médio de frutos (frutos ha $\mathrm{a}^{-1}$ ) e o rendimento $\left(\mathrm{kg} \mathrm{ha} \mathrm{h}^{-1}\right)$ de abobrinha foram influenciados tanto pela cobertura plástica do solo quanto pela água carbonatada, sendo significativa a interação entre os dois fatores. Entretanto, não foram observadas diferenças significativas, quando comparados o número médio de frutos (frutos ha ${ }^{-1}$ ) dos tratamentos sem cobertura plástica aos seus respectivos pares com cobertura, mesmo fato acontecendo a produtividade ( $\mathrm{kg} \mathrm{ha}^{-1}$ ) de abobrinha (Tabela 2).

Modelos quadráticos foram ajustados para número de frutos, explicando 93,2\% e 79,7\% dos dados para solo com cobertura e solo nu, respectivamente (Figura 1). Para o solo coberto, a produção maior foi de 95.275 frutos ha ${ }^{-1}$ para dose de $68,5 \mathrm{~kg} \mathrm{ha}^{-1}$ de $\mathrm{CO}_{2}$, enquanto para solo nu, a produção maior foi de 77.908 frutos $\mathrm{ha}^{-1}$ para dose de $90,6 \mathrm{~kg} \mathrm{ha}^{-1}$ de $\mathrm{CO}_{2}$.

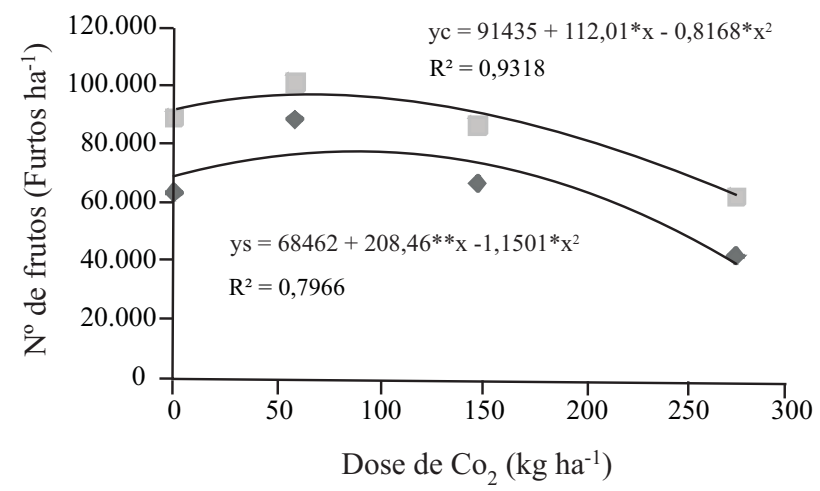

Figura 1 - Número de frutos (frutos $\mathrm{ha}^{-1}$ ) de abobrinha cv. Caserta sob doses de $\mathrm{CO}_{2}\left(\mathrm{~kg} \mathrm{ha}^{-1}\right)$ em solo com (Yc) e sem cobertura plástica (Ys)

Tabela 1 - Equação de regressão para a área foliar $\left(\mathrm{cm}^{2}\right)$ de abobrinha cv. Caserta aos 68 Dias Após o Transplante (DAT) em função das doses de $\mathrm{CO}_{2}(\mathrm{D})$ via água de irrigação e da cobertura do solo

\begin{tabular}{ccc}
\hline Área foliar $\left(\mathrm{cm}^{2}\right)$ & Equação & $\mathrm{R}^{2}$ \\
\hline Solo coberto & $\mathrm{Y}=10831,972+13,467^{*} \mathrm{D}-0,078^{*} \mathrm{D}^{2}$ & 0,570 \\
Solo $\mathrm{nu}$ & $\mathrm{Y}=7594,208+27,258 \mathrm{D}-0,105^{*} \mathrm{D}^{2}$ & 0,531 \\
\hline
\end{tabular}

* significativo a $5 \%$ de probabilidade pelo teste $\mathrm{t}$

Tabela 2 - Número de frutos (frutos ha $\left.{ }^{-1}\right)$ e produtividade $\left(\mathrm{kg} \mathrm{ha}^{-1}\right)$ de abobrinha cv. Caserta cultivada com água carbonatada em solo com e sem cobertura plástica

\begin{tabular}{ccccc}
\hline \multirow{2}{*}{ Dose de $\mathrm{CO}_{2}\left(\mathrm{~kg} \mathrm{ha}^{-1}\right)$} & \multicolumn{2}{c}{ Número de Frutos $\left(\right.$ Frutos ha $\left.{ }^{-1}\right)$} & \multicolumn{2}{c}{ Produtividade $\left(\mathrm{kg} \mathrm{ha}^{-1}\right)$} \\
\cline { 2 - 5 } & Sem Cobertura & Com cobertura & Sem cobertura & Com cobertura \\
\hline 0 & $63.000 \mathrm{a}$ & $88.750 \mathrm{a}$ & $9.327 \mathrm{a}$ & $14.427 \mathrm{a}$ \\
59 & $88.333 \mathrm{a}$ & $100.889 \mathrm{a}$ & $14.322 \mathrm{a}$ & $16.356 \mathrm{a}$ \\
148 & $66.250 \mathrm{a}$ & $86.250 \mathrm{a}$ & $9.331 \mathrm{a}$ & $13.482 \mathrm{a}$ \\
\hline 274 & $41.000 \mathrm{a}$ & $61.667 \mathrm{a}$ & $5.886 \mathrm{a}$ & $7.886 \mathrm{a}$ \\
\hline
\end{tabular}

Para variável, média seguida de mesma letra na horizontal, não diferiram estatisticamente entre si a $5 \%$ de probabilidade pelo teste de Tukey 
O aumento na produtividade como conseqüência da irrigação com água carbonatada e uso de cobertura plástica coincide com outros estudos realizados sobre pepino, tomate, melão, pimentão e alface (BRANCO et al. 2007; CARARO, 2000; FURLAN et. al., 2001; FURLAN et al., 2002; GOMES et al., 2005; GURI et al., 1999; IBRAHIM, 1992; PINTO et al., 2001; REZENDE et al., 2003 e TAMAGI et al., 2007). O aumento observado na área foliar é evidência dos efeitos causados pelo uso de $\mathrm{CO}_{2}$ e cobertura plástica, que propiciaram aumento do número de frutos pela maior produção de fotoassimilados.

Verificou-se, pela analise de variância, que o rendimento comercial $\left(\mathrm{kg} \mathrm{ha}{ }^{-1}\right)$ de abobrinha foi influenciado em nível de $1 \%$ de probabilidade pelas doses de $\mathrm{CO}_{2}$ e pela cobertura do solo, sem, entretanto, haver uma interação entre os dois fatores. Os tratamentos com uma determinada dose de $\mathrm{CO}_{2}$ com cobertura plástica, supostamente pela melhoria nas condições térmicas e pela boa manutenção hídrica do solo, foram mais produtivos que seus pares em solo nu. Concordando com os trabalhos de Silva (2002).

Modelos quadráticos foram ajustados para produtividade, explicando $96,3 \%$ e $67,7 \%$ dos dados para com cobertura e solo nu, respectivamente (Figura 2). Para o solo coberto, a produtividade ótima foi $15.433,7 \mathrm{~kg} \mathrm{ha}^{-1}$ com a dose de $58,65 \mathrm{~kg} \mathrm{ha}^{-1}$ de $\mathrm{CO}_{2}$, enquanto para solo $\mathrm{nu}$, a maior produtividade foi de $11.820,8 \mathrm{~kg} \mathrm{ha}^{-1}$ para doses de $84,51 \mathrm{~kg} \mathrm{ha}^{-1}$ de $\mathrm{CO}_{2}$ (Figura 2). A média geral do experimento foi de $11.378 \mathrm{~kg} \mathrm{ha}^{-1}$, situando-se na faixa entre 10 e $20 \mathrm{t} \mathrm{ha}^{-1}$, indicado por Filgueira (2008) como bom rendimento. A produtividade obtida com a aplicação de $58,65 \mathrm{~kg}$ de $\mathrm{CO}_{2}$ e a cobertura plástica foi $65,4 \%$ superior ao do tratamento testemunha que foi $9.328 \mathrm{~kg} \mathrm{ha}^{-1}$. Esses dados são consistentes com aqueles encontrados por Pinto et al. (2001) que obtiveram, com aplicação de $50 \mathrm{~kg} \mathrm{ha}^{-1}$ de $\mathrm{CO}_{2}$ via água, aumento de $70 \%$ na produtividade comercial do meloeiro. Outros autores utilizando água carbonatada também verificaram incremento na produção (CARARO, 2000; GOMES et al., 2005; GURI et al., 1999 e IBRAHIM, 1992). Contrariamente, Hartz e Holt (1991) estudaram o efeito do $\mathrm{CO}_{2}$ aplicado via água de irrigação sobre as culturas de tomate e de abóbora em campo e não observaram qualquer aumento de produção. Segundo Storlie e Heckman (1996), apesar dos resultados positivos da água carbonatada para as culturas, existe uma série de fatores não completamente entendidos que podem levar à obtenção de resultados adversos, fazendo com que, em termos práticos, ainda não seja recomendado o uso desta técnica. Entretanto, em nosso trabalho, os resultados de produção mostraram-se bastante favoráveis ao uso desta técnica, sendo possível ajustar doses de $\mathrm{CO}_{2}$ que associada ou não ao uso da cobertura plástica propicie maiores produtividades com o uso de uma menor quantidade do gás aplicado via irrigação.

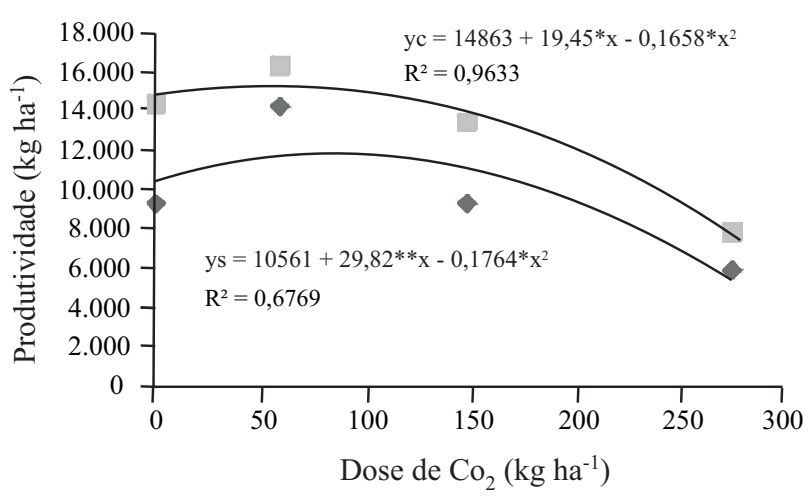

Figura 2 - Produtividade $\left(\mathrm{kg} \mathrm{ha}^{-1}\right)$ de abobrinha cv. Caserta sob doses de $\mathrm{CO}_{2}\left(\mathrm{~kg} \mathrm{ha}^{-1}\right)$ em solo com $(\mathrm{Yc})$ e sem cobertura plástica (Ys)

\section{Conclusões}

1. A aplicação do $\mathrm{CO}_{2}$ via água de irrigação associada à cobertura plástica no solo propiciaram aumento na área foliar, números de fruto e produtividade na cultura da abobrinha de moita, sendo possível ajustar uma ótima dose de CO.

2. A aplicação do $\mathrm{CO}_{2}$ via água de irrigação propiciou aumento na área foliar, números de fruto e produtividade na cultura da abobrinha de moita, sendo possível ajustar uma ótima dose de $\mathrm{CO}_{2}$.

3. A dose de $\mathrm{CO}_{2}$ associada ao uso da cobertura plástica propiciou com o uso de uma menor quantidade do gás a obtenção de maiores produtividades.

4. É necessário aplicar uma dose de $\mathrm{CO}_{2}$ adequada para obtenção de efeitos positivos sobre a cultura da abobrinha.

\section{Agradecimentos}

Os autores agradecem ao Prof. Dr. João Tessarioli Neto (in memorian) pelo apoio na execução do experimento e a FAPESP pelo apoio financeiro na execução do projeto. $\mathrm{O}$ primeiro autor agradece à Universidade Federal de Roraima pela oportunidade do doutorado e à CAPES pela bolsa de PICDT. 


\section{Referências}

ABDUL-BAKI, A.; SPENCE, C; HOOVER, R. Black polyethylene mulch doubled yield of fresh-market field tomatoes. Hortscience, v. 27, n. 07, p. 787-789, 1992.

ARAÚJO, W. F. et al. Estimativa da área foliar de abobrinha usando método não destrutivo. Horticultura Brasileira, v. 18, p. 327-328, 2000.

AZEVEDO, B. M. et al. Rendimento da pimenteira em função de lâminas de irrigação. Revista Ciência Agronômica, v. 36, n. 03, p. 268-273, 2005.

BRANCO, R. et al. Enxertia e água de irrigação carbonatada no transporte de $15 \mathrm{~N}$ e na produção do tomateiro. Revista Brasileira Engenharia Agrícola e Ambiental, v. 11, n. 04, p. 374-379, 2007.

CARARO, D. C. Efeitos de diferentes lâminas de água na presença e ausência de $\mathrm{CO}_{2}$ injetado na água de irrigação sobre a cultura do tomate (Lycopersicon esculentum Mill.) cultivado em estufa. 2000. $70 \mathrm{f}$, Dissertação (Mestrado em Irrigação e Drenagem) - Escola Superior de Agricultura "Luiz de Queiroz", Universidade de São Paulo, Piracicaba.

CHAVES, S. W. P. et al. Rendimento da pimenteira em função de doses de nitrogênio. Revista Ciência Agronômica, v. 37, n. 01, p. 19-24, 2006.

DOORENBOS, J.; PRUITT, W. O. Necessidade hídrica das culturas. Campina Grande: UFPB, 1997. 204 p. (Estudos FAO. Irrigação e Drenagem, 24)

FILGUEIRA, F. A. R. Novo Manual de olericultura: agrotecnologia moderna na produção e comercialização de hortaliça. Viçosa: UFV, 2008. 421 p.

FURLAN, R. A. et al. Dióxido de carbono aplicado via água de irrigação na cultura da alface. Horticultura Brasileira, v. 19, n. 01, p. 25-29, 2001.

FURLAN, R. A. et al. Lâmina de irrigação e aplicação de $\mathrm{CO}_{2}$ na produção de pimentão cv. Mayata, em ambiente protegido. Horticultura brasileira, v. 20, n. 04, p. 547-550, 2002.

GOMES, T. M. et al. Aplicação de doses de $\mathrm{CO}_{2}$ via água de irrigação na cultura da alface. Horticultura brasileira, v. 23, n. 02, p. 316-319, 2005.

GURI, S.; MARFA, O.; SAVÉ, R. Efecto de la irrigación carbônica em la producción de un cultivo de pimiento. Barcelona: IRTA, Departamento de Tecnologia Hortícola, $1999.6 \mathrm{p}$.

HARTZ, T. K.; HOLT, D. B. Root-zone Carbon Dioxide Enrichment in field does not improve tomato or cucumber yield. HortScience, v. 26, n. 11, p. 14-23, 1991.

HATZ, T. K.; HOCHMUTH, G. J. Fertility management of drip-irrigated vegetables. HortTechnology, v. 06, n. 02, p. 168-172, 1996.
IBRAHIM, A. Response of plant to irrigation with $\mathrm{CO}_{2}$ enrichment water. Acta Horticulturae, v. 323, p. 205-214, 1992.

MOORE, F. D. Potential for irrigation with carbon dioxide. Acta Horticulturae, n. 278, p.171-178, 1990.

MUDRIK, V. A. et al. Effect of increased $\mathrm{CO} 2$ concentration on growth, photosynthesis and composition of Pisum sativum L. plant. Russian Journal of Plant Physiology, v. 44, p. 165-171, 1997.

NASCIMENTO, I. B. et al. Desenvolvimento vegetativo do melão cultivado sob diferentes intensidades de preparo de solo com e sem mulching. In: CONGRESSO BRASILEIRO DE ENGENHARIA AGRÍCOLA, 29., 2000, Fortaleza. Anais... Fortaleza: SBEA, 2000. 1 CD-ROM.

PINTO, J. M et al. Aplicação de $\mathrm{CO}_{2}$ via água de irrigação em relação à produtividade do meloeiro. Scientia Agricola, v. 58, n. 01, p. 27-31, 2001.

RAIJ, B. Van. et al. Recomendações de adubação e calagem para o Estado de São Paulo. 2. ed. Campinas: IAC, 1996. 285 p. (Boletim Técnico, 100).

REGO, J. L. et al. Produtividade de crisântemo em função de níveis de irrigação. Horticultura Brasileira, v. 27, n. 01, p. 45-48, 2009.

REZENDE, F. C. et al. $\mathrm{CO}_{2}$ and irrigation in relation to yield and water use of the bell pepper crop. Scientia Agricola, v. 60, n. 01, p. 7-12, 2003.

SAMPAIO, R. A.; ARAÚJO, W. F. Importância de cobertura plástica do solo sobre o cultivo de hortaliças. Agropecuária Técnica, v. 22, n. 01/02, p. 1-12, 2001.

SENTELHAS, P. C. et al. Coeficiente do tanque Classe A (Kp) para estimativa da evapotranspiração diária. In: CONGRESSO BRASILEIRO DE AGROMETEOROLOGIA, 11., 1999, Florianópolis. Anais... Florianópolis: SBA, 1999. 1 CD-ROM.

SILVA, E. F. F. et al. Determinação da salinidade do solo utilizando extratores de cápsulas porosas e soluções diluídas (compact disc). In: CONGRESSO BRASILEIRO DE ENGENHARIA AGRÍCOLA, 28., 1999, Pelotas. Anais... Pelotas: SBEA, 1999.

SILVA, M. C. C. Crescimento, produtividade e qualidade de frutos do meloeiro sob diferentes níveis de salinidade da água de irrigação e cobertura do solo. 2002. 65 f. Dissertação (Mestrado em Fitotecnia) - Escola Superior de Agricultura de Mossoró, Mossoró.

STORLIE, C. A.; HECKMAN. J. R. Soil, plant and canopy responses to carbonated irrigation water. HortTechnology, v. 06, n. 02, p. 111-114, 1996.

TAMAGI, J. T. et al. Efeito do $\mathrm{CO}_{2}$ aplicado via água de irrigação sobre a cultura da alface (Lactuca sativa L.). Irriga, v. 12, n. 04, p. 492-504, 2007. 